\title{
Cardio Vascular Disease Classification Ensemble Optimization using Genetic Algorithm and Neural Network
}

\author{
Jagwant Singh ${ }^{1}$ and Rajinder Kaur ${ }^{2}$ \\ Department of Computer Science Engineering, Chandigarh University, Gurgoan - 140413, Punjab, \\ India; jagwant.bhangu@gmail.com, rajinder.cse@gmail.com
}

\begin{abstract}
Objective: To develop a new technique for the detection of heart disease and to build the detection system based on fuzzy logic algorithm for extraction of features by applying neural network classifier of heart disease. Methods/Statistical analysis: The disease dataset is classified by using Fuzzy logic, genetic algorithm and training is done by neural network by the extracting features. The image is tested on the basis of features of dataset and the extracted images. Findings: The accuracy is improved up to $99.97 \%$. The error rate is reduced, it is $.987 \%$. Application/Improvements: This paper presented the ECG signal modeling along with classification of diseases using fuzzy logic, Genetic Algorithm and Neural Network with improved accuracy and less error rate.
\end{abstract}

Keywords: Accuracy, Error Rate, Fuzzy Logic, Genetic Algorithm, Heart Disease, Neural Network

\section{Introduction}

The electrocardiogram is a demonstration of body surface potentials generated by the electrical action of the heart. The recording and analysis of the ECG has a very long impact in the past and is a significant portion of the clinical valuation of an individual's cardiac status and general health ${ }^{1-3}$. ECG can also be used to conclude heart rate by scheming the time between consecutive QRS complexes. It is significant to be able to compute the heart rate between every beat as it makes it to look at the beat to beat inconsistency in heart rate. Decrease heart rate unevenness is therefore used as a quantifiable indication of reduced vagal activity. The additional, reduced heart rate inconsistency has been shown to expect sudden death in patients with myocardial infarction.

Signal processing is immense popular systems for ECG analysis. The goal ofECG processing is to give the flawlessness of precision, reproducibility and the expulsion of data not accessible from the signals only 1 . As a rule, the ECG is recorded during debilitating conditions such that the signal is raided by various sorts of clamors; now and again start from another physiological procedure of the body. Consequently, clamor diminishment speaks to another huge motivation behind ECG signal handling 5 , Electrocardiographic signs might be recorded on a long timescale for the reason to recognize unpredictably happening battling in the heart beat. Transmission of signs crosswise over open beneficiary systems is another solicitation in which substantial measure of information are embroiled. For both areas, information pressure is a critical operation and speaks to another motivation behind ECG signal handling. Basic algorithm of ECG signals is shown in Figure 1.

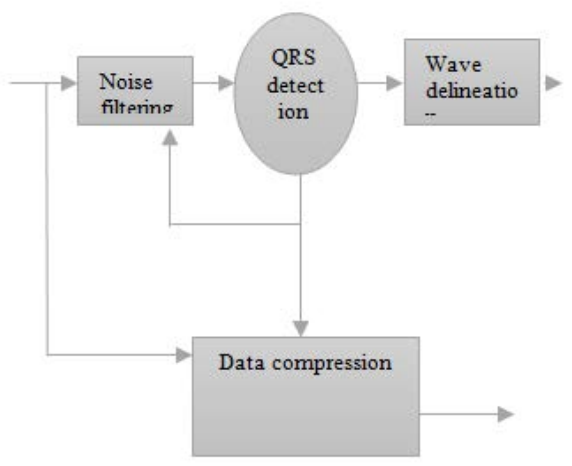

Storage/transmission

Figure 1. Basic algorithm of ECG signal. 
Signal processing has added to another comprehension of the ECG and its dynamic properties as expressed by change in musicality and beat morphology. For instance, techniques have been produced that recognize motions associated with the cardiovascular framework and reflected by unobtrusive variety in heart rate. The disclosure of low level changes in T wave sufficiency is an extra case of oscillatory execution that has been set up as a pointer of expanded danger for sudden life undermining arrhythmias. Neither of these two oscillatory sign properties can be evident by the bare eye from a run of the mill ECG printout.

A wide range of ECG examination, whether it takes resting ECG investigation, stress testing, wandering screen or thought care observing are the fundamental set of calculations that express the sign regarding unique sorts of clamor and relics ${ }^{7}$. In spite of the fact that these algorithms are consistently actualized to work in consecutive request as created by the QRS indicator are some of the time consolidated into alternate calculations to enhance execution 8 .

Table 1 shows the standard ECG data that defines different waves, namely, $\mathrm{P}$ wave, $\mathrm{R}$ wave, $\mathrm{Q}$ wave and $\mathrm{T}$ wave, on the basis of amplitude and duration time.
Table 1. Standard ECG Data

\begin{tabular}{|c|c|c|c|}
\hline Amplitude & Amplitude & Duration Time & Duration time \\
\hline $\mathrm{P}$ wave & $0.25 \mathrm{Mv}$ & P-R interval & 0.12 to $0.20 \mathrm{sec}$ \\
\hline $\mathrm{R}$ wave & $1.60 \mathrm{Mv}$ & Q-T interval & 0.35 to $0.44 \mathrm{sec}$ \\
\hline Q wave & $\begin{array}{l}25 \% \text { of } \mathrm{R} \\
\text { wave }\end{array}$ & S-T interval & 0.05 to $0.15 \mathrm{sec}$ \\
\hline \multirow[t]{5}{*}{$\mathrm{T}$ wave } & $\begin{array}{l}0.1 \text { to } \\
0.5 \mathrm{mV}\end{array}$ & $\mathrm{P}$ wave interval & $0.11 \mathrm{sec}$ \\
\hline & & QRS complex & $0.09 \mathrm{sec}$ \\
\hline & & PR segment & 0.06 to $0.10 \mathrm{sec}$ \\
\hline & & ST segment & -0.10 to $0.15 \mathrm{sec}$ \\
\hline & & $\mathrm{T}$ wave & Varies \\
\hline
\end{tabular}

In this proposed framework, the benefits of GA and neural networks are joined to anticipate the danger of cardiovascular disease. In numerous applications, learning that depicts craved framework conduct is contained in datasets. At the point when datasets contain learning about the framework to be composed, a neural system guarantees an answer since it can prepare itself from the datasets. Neural systems are versatile models for information examination especially appropriate for taking care of nonlinear capacities. By consolidating

Table 2. Comparison of Techniques

\begin{tabular}{|c|c|c|c|}
\hline Author & Technique/ Method & Advantages & Results \\
\hline $\begin{array}{l}\text { Kaustubh Manik Gaik- } \\
\text { wad, } 2014 \text { [8] }\end{array}$ & $\begin{array}{l}\text { Butter worth } \\
\text { Approximations }\end{array}$ & $\begin{array}{l}\text { The consequences of before filtration } \\
\text { and after filtration are depicting in the } \\
\text { paper }\end{array}$ & Noise removal \\
\hline Neha Dhage, 2014 [9] & $\begin{array}{l}\text { Threshold free detection } \\
\text { technique }\end{array}$ & $\begin{array}{l}\text { Normal maximum and minimum heart } \\
\text { rate. }\end{array}$ & Accuracy $=$ good \\
\hline $\begin{array}{l}\text { S. Vishnu Gopeka, } \\
2014[10]\end{array}$ & $\begin{array}{l}\text { Hence Multiscale } \\
\text { Mathematical Morphology }\end{array}$ & Noise reduction. & Noise reduction. \\
\hline $\begin{array}{l}\text { Abdelhaq Ouelli, } 2014 \\
{[11]}\end{array}$ & neural networks & $\begin{array}{l}\text { The performance of the networks for } \\
\text { speed of convergence and accuracy } \\
\text { classifications are evaluated for various } \\
\text { ECG data types. }\end{array}$ & Accuracy $=$ good \\
\hline M. K. Islam, 2012 [12] & MATLAB functions & detection of any abnormalities in ECG & Great accuracy and ease. \\
\hline Qian Zheng, 2014 [13] & $\begin{array}{l}\text { Multi-Resolution Support } \\
\text { Vector Machine algorithm }\end{array}$ & $\begin{array}{l}\text { Consequences show that the algorithm } \\
\text { can productively extract original QRS } \\
\text { complex waves and T waves regardless } \\
\text { of noise magnitude and distinguish the } \\
\text { ST segment morphological anomalies. }\end{array}$ & $\begin{array}{l}\text { Average } \mathrm{T} \text { wave appreciation } \\
\text { accuracy rate of } 97.5 \% \text { and } \mathrm{ST} \\
\text { irregularity detection accuracy } \\
\text { rate of } 93 \% \text {. }\end{array}$ \\
\hline $\begin{array}{l}\text { Menta Srinivasulu, } \\
2014[14]\end{array}$ & FIR and IIR.FIR filters & $\begin{array}{l}\text { Noise removal using FIR digital filter is } \\
\text { better alternative in assessment with IIR } \\
\text { digital filter. }\end{array}$ & Noise reduction. \\
\hline
\end{tabular}


the enhancement strategy of hereditary calculation with the learning force of neural system, a model with better prescient exactness can be determined. Further to improve the outcome the fuzzy logic has been used.

\section{A Glance of Existing Techniques}

ECGs are analyzed by the doctors. The comprehension may differ by doctor to medicinal specialist. Thus, this work is about the consistency in the investigation of the ECG signals with the goal that they should be analyzed and deciphered precisely independent of the doctor. This would make an early activity expected for the issues and numerous lives may be spared. Numerous works have been done already. However, this work presents Electrocardiogram (ECG) orders to analyze patient's condition is fundamental.

Table 2 shows the comparison of the techniques previously proposed by different authors. ${ }^{.1-1}$

\section{Proposed Work}

Proposed system has been developed to classify the heart disease using neural network, fuzzy logic and genetic algorithm. The subsequent steps demonstrate the variety of phases that need to be accomplished:

Step-1: Upload given dataset for 30 samples.

Step-2: Feature extraction using GA.

Step-3: Optimize Fitness Function based on fuzzy logic and get fuzzification of dataset.

Step-4: Implement neural network for classification purpose. It has basically two steps:

- Training phase and

- Testing Phase

Step-5: Diseases Classification

Step-6: Calculate performance metrics like Accuracy and error rate.

\subsection{Dataset Acquisition}

Data set acquisition is the first step of our proposed technique. Dataset in the form of .mat file has been taken ${ }^{15-17}$.

\subsubsection{Feature Extraction}

Feature reduction has been done using GA on separated signal dataset then feature count and feature values are plotted. After that Fitness function will be optimized as below:

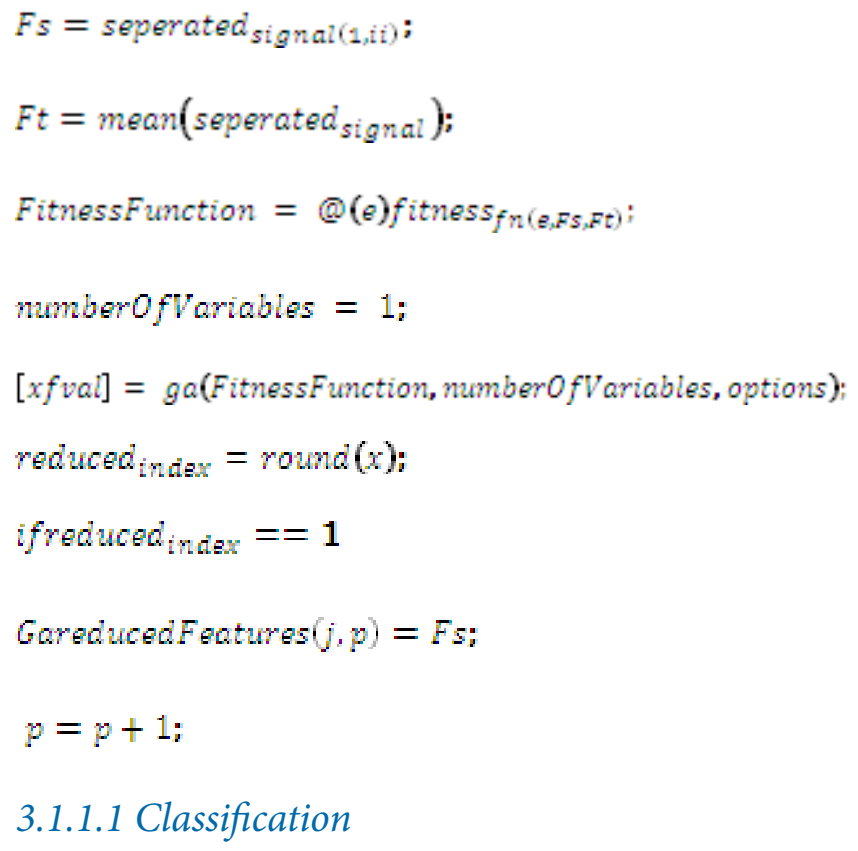

\subsubsection{Classification}

Then classification of trained data will be done using NN. Neural network is a network of "neuron like" units entitled as nodes.

\subsubsection{Training Using NN}

The training process includes the conjugating the neural network then train them about data features. Training procedure benefits in creation of information base. Later it is used in matching and decision level.

\subsubsection{Testing using NN}

The testing phase include the retrieving the trained dataset. The trained network system is displayed by means of trained features. The network, acting as selectively recovers top-matched, a classifier, related, alike data values as per that of dataset from the database and are presented to user. 


\section{a) Algorithm for Training Phase}

setun $N N$ and also vrevare the subsequent factors

as: number of layars' epochs;

learning ${ }_{\text {rate; }}$ permissible error;

input: network, training set

do

foreach image in training set

fuse the removed characteristics hooked on

to a single characteristics matrix;

untila solitary characteristic of vector

matrix is made;

do

train the given network regarding class

labels as well as feature vectors;

untilending criterion epochs $=2000$ is fulfilled

output: a trained neural network.

b) Algorithm for Testing Phase:

input: dataet.

load the input dataset;

extract its reduced features;

load the fused features database;

output: set of similar data values if present;

if not, display then also.

\section{Results and Discussion}

The whole simulation is done in MATLAB 2010 a environment to classify the data samples having disease or not. Table 3 and Figure 2 describes the obtained values of accuracy and error rate for 30 samples in the dataset of heart diseases.
Table 3. Parameter Evaluation

\begin{tabular}{lcc}
\hline Sample No. & Accuracy $(\%)$ & Error rate (\%) \\
\hline 1. & 99.197 & .807 \\
2. & 99.237 & .987 \\
3. & 99.567 & .867 \\
4. & 99.347 & .907 \\
5. & 99.237 & .667 \\
6. & 99.157 & .907 \\
7. & 99.167 & .667 \\
8. & 99.127 & .447 \\
9. & 99.567 & .787 \\
10. & 99.777 & .447 \\
11. & 99.837 & .337 \\
12. & 99.327 & .997 \\
13. & 99.897 & .777 \\
14. & 99.107 & .877 \\
15. & 99.297 & .907 \\
16. & 99.597 & .770 \\
17. & 99.497 & .987 \\
18. & 99.947 & .607 \\
19. & 99.277 & .677 \\
20. & 99.657 & .887 \\
21. & 99.407 & .547 \\
22. & 99.307 & .657 \\
23. & 99.567 & .447 \\
24. & 99.477 & .987 \\
25. & 99.107 & .767 \\
26. & 99.237 & .757 \\
27. & 99.217 & .877 \\
28. & 99.117 & .657 \\
29. & 99.107 & .987 \\
30. & 99.157 & .777 \\
\hline & & \\
& &
\end{tabular}

Parameter Evaluation

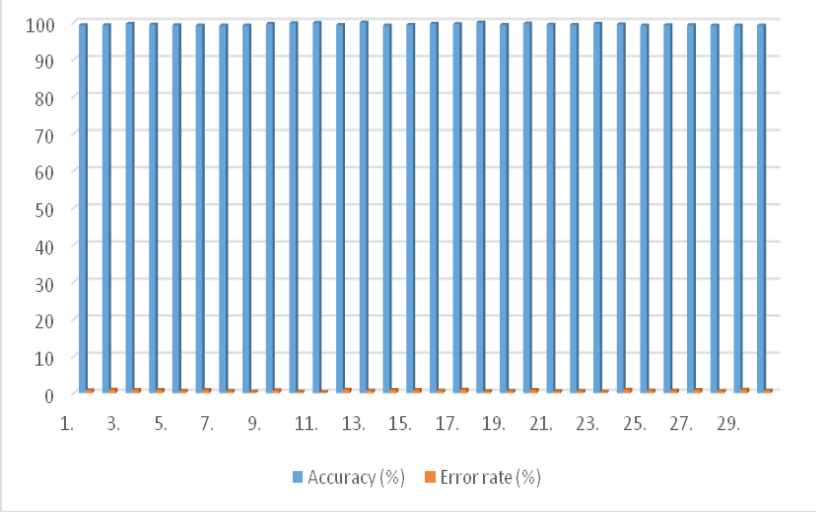

Figure 2. Parameter Evaluation. 


\section{Conclusion and Future Scope}

This paper presented the heart disease prediction system by utilizing Fuzzy logic for feature extraction, GA for feature reduction and NN for classification. Simulation results shows that the obtained values of error rate and accuracy for proposed tested image has been found out to be error rate $.987 \%$ and accuracy $=99.97 \%$ that are satisfactory results. Future scope lies in the use of other classifiers like SVM that has multidimensional data and use of feature reduction algorithms genetic algorithm, so that accuracy rate can be enhanced. SVMs deliver a unique solution, since the optimality problem is convex. This is an advantage compared to Neural Networks, which have multiple solutions associated with local minima and for this reason may not be robust over different samples.

\section{References}

1. Rajendra A, Krishnan S M, Spaan J A, Suri J S. Advances in cardiac signal processing. Edition. Berlin: Springer; 2007.

2. Proakis J G, Manolakis D G. Digital Signal Processing: Principles, Algorithms, and Applications: Prentice-Hall; 1999.

3. Mother K. Introduction to Electrocardiography, Tufts-New England Medical Center, Spring; 2008.

4. Chattopadhyay A. Design and Simulation Approach Introduced to ECG Peak Detection with Study on Different Cardiovascular Diseases, International Journal of Scientific and Research Publications.2012 Dec;2(12):1-7.

5. Wook A C, Ramakrishna R S. A genetic algorithm for shortest path routing problem and the sizing of populations, Evolutionary Computation, IEEE Transactions. 2002.p.566-79.

6. Afsar F A, Arif M. Detection of ST Segment Deviation Episodes in the ECG using KLT with an Ensemble Neural Classifier, Emerging Technologies, 2007. ICET 2007. International Conference on. IEEE. 2007.

7. Matthias C. Filtering and Signal-Averaging Algorithms for Raw ECG Signals. ESE. 2010;482:1-16.
8. Manik G K, Chavan M S. Removal of high frequency noise from ECG signal using digital IIR butterworth filter. Wireless Computing and Networking (GCWCN), 2014 IEEE Global Conference on. IEEE; 2014.

9. Neha D, Madhe S. An automated methodology for FECG extraction and Fetal Heart Rate monitoring using Independent Component Analysis. Advanced Communication Control and Computing Technologies (ICACCCT), 2014 International Conference on. IEEE; 2014.

10. Neha D, Madhe S. An automated methodology for FECG extraction and Fetal Heart Rate monitoring using Independent Component Analysis. Advanced Communication Control and Computing Technologies (ICACCCT), 2014 International Conference on. IEEE; 2014.

11. Abdelhaq O, Elhadadi B, Bouikhalene B. Multivariate autoregressive modeling for cardiac arrhythmia classification using multilayer perceptron neural networks. Multimedia Computing and Systems (ICMCS), 2014 International Conference on. IEEE; 2014.

12. Islam MK. Study and Analysis of ECG Signal Using MATLAB \& LABVIEW as Effective Tools.2002;4:404-8.

13. Qian Z. A novel multi-resolution SVM (MR-SVM) algorithm to detect ECG signal anomaly in WE-CARE project. Biosignals and Biorobotics Conference (BRC), 2013 ISSNIP. IEEE; 2013.

14. Menta S, Reddy C. Novel Method To Find The Parameter For Noise Removal From Multi-Channel Ecg Waveforms, IJRET: International Journal of Research in Engineering and Technology. 2014;3:395-400.

15. Shathesh S, Durairaj M. An Intelligent Hybrid Mechanism to Predict the Risk of Cardio Vascular Disease, Indian Journal of Science and Technology. 2016 Jan;9(4):1-8.

16. Kaghed H N, Al-Shamery S E, Al-Khuzaie F E K. Multiple Sequence Alignment based on Developed Genetic Algorithm , Indian Journal of Science and Technology, 2016 Jan;9(2):1-7.

17. Noersasongko E, Julfia F T, Syukur A, Purwanto , Pramunendar R A, Supriyanto C. A Tourism Arrival Forecasting using Genetic Algorithm based Neural Network, Indian Journal of Science and Technology. 2016 Jan;9(4):1-5. 